\title{
Is there a correlation between sleep disordered breathing and maxillary expansion? A retrospective study based on cephalometric assessment and questionnaires
}

\begin{abstract}
Aim: This study aimed to document the effect of maxillary expansion (ME) during childhood on Sleep Disordered Breathing (SDB) symptoms in adults. The secondary aim is to try to find a screening tool for daily use in the orthodontic/dental office in children who are not yet diagnosed with OSA. We try to develop a tool that could help us in deciding which children should be referred for OSA screening, possibly including polysomnography, based on the cephalometric radiograph and the symptoms they report.
\end{abstract}

Methods: This is a retrospective study (S) focusing on cephalometric measurements performed on 27 children (C), which had received maxillary expansion (RCS group) and as adults (A) attended a post-treatment follow-up on average 21.1 $( \pm 7.24)$ years later (RAS group). A cephalometric radiograph before treatment and a cephalometric radiograph at post-treatment follow-up were traced. These were compared with untreated control (Co) groups of 50 subjects each (RCCo group and RACo group). Questionnaires related to SDB symptoms were administered in the RAS and RACo groups.

Results: Small changes in cephalometric measurements were seen comparing patients with (RCS group and RAS group) and without (RCCo group and RACo group) maxillary expansion. Questionnaires were answered similarly by the study (RAS group) and control group (RACo group).

Conclusions: Small cephalometric changes were seen between groups.

Current knowledge: The favorable effect of expansion of the maxilla on SDB symptoms has been demonstrated in several studies, the aim of this research was to document if patients treated with maxillary expansion during childhood can benefit from this intervention concerning Sleep Disordered Breathing (SDB) at adult age.

Study impact: Maxillary expansion during childhood might improve SDB symptoms at adult age.

Keywords: sleep disordered breathing, maxillary expansion, cephalometry, snoring, neuro-cognitive disorders
Volume I Issue 4 - 2017

Detailleur Valentine,' 'Van Dyck Julie,' Cadenas de Llano Pérula Maria,' Buyse Bertien, ${ }^{2}$ Fieuws Steffen, ${ }^{3}$ Verdonck Anna ${ }^{\prime}$ Politis Constantinus, ${ }^{4}$ Willems Guy'

'Department of Oral Health Sciences-Orthodontics, University Hospitals Leuven, Belgium

${ }^{2}$ Department of Pulmonology, University Hospitals Leuven, Belgium

${ }^{3}$ Interuniversity Institute for Biostatistics and statistical Bioinformatics, Belgium

${ }^{4}$ Department of Imaging and Pathology, University Hospitals Leuven, Belgium

Correspondence: Willems G, Department of Oral Health Sciences-Orthodontics, Katholieke Universiteit Leuven, Kapucijnenvoer 7,3000 LEUVEN, Belgium, Tel +3216332558, Fax +3216337578, Email guy.willems@med.kuleuven.be

Received: November 10, 2017 | Published: December 07, 2017
Abbreviations: SDB, sleep disordered breathing; OSA, obstructive sleep apnea; ME, maxillary expansion; RME, rapid maxillary expansion; ESS, epworth sleepiness scale; SOS, snore outcomes survey; SPBS, spouse/bed partner survey; MPT, maximum palatal thickness; PAS, posterior airway space; R, retrospective; C, child; A, adult; S, study; Co, control m-RCS, retrospective children study group; -RAS, retrospective adult study group; RCCo, retrospective children control group; RACo, retrospective adult control group

\section{Introduction}

Sleep Disordered Breathing (SDB) is a prevalent disorder in youngsters and adults. (Appendix 1: List of Abbreviations) Sleeprelated breathing disorders are divided into four sections according to the International Classification of Sleep Disorders, Third Edition
(2014): OSAs, central sleep apnea (CSA) syndromes, sleep-related hypoventilation disorders, and sleep-related hypoxemia disorder. ${ }^{1}$ In 2008 the incidence of OSA was estimated at 3 to $7 \%$ in men and 2 to $5 \%$ in women in the general population, which is therefore often higher than expected. ${ }^{2}$ Nowadays, this number has substantially increased, due to the obesity pandemic. ${ }^{3}$ Body Mass Index is a considerable risk factor for SDB: severity of the symptoms increases with higher body weight. ${ }^{4}$ The incidence of snoring and OSA in the general population is also higher in men, although the difference in prevalence between men and women differs depending on age. ${ }^{4-6}$ The severity of the disorder is varied. Besides disturbed sleep of the patient and his companion, other signs can be present as well, such as tiredness during daytime, neuro-cognitive disorders, cardiovascular diseases and breathing problems, significantly undermining quality of life which is possibly leading to higher mortality rates. ${ }^{7}$ 
The gold standard for detection of OSA is still polysomnography. Treatment modalities for SDB are Continuous Positive Airway Pressure (CPAP), lifestyle adaptation by losing weight (and lowering medication or alcohol consumption), positional training and Mandibular Advancement Devices (MAD). When a craniofacial anomaly is present, surgery of hard and/or soft tissues can be performed. ${ }^{8,9}$ Children can be treated with adenotonsillectomy, medication (as intranasal steroids), weight reduction, oral appliances or $\mathrm{CPAP}^{10}$

In the literature, it has been suggested that aberrant maxillary morphology could be related to SDB and that maxillary expansion might improve OSA. Seto, et al. ${ }^{11}$ observed a difference in maxillary morphology between OSA-patients and non-snoring patients. Besides, a higher percentage of the OSA-patients showed posterior transverse discrepancies such as a uni-or bilateral cross bite or a bilateral edgeto-edge cusp relationship. OSA-patients had narrower and smaller maxillary arches. ${ }^{11}$ Katyal, et al. ${ }^{12}$ also concluded that frequency of palatal cross bite was higher in children at high risk of SDB. ${ }^{12}$

It is possible that an upper airway obstruction during childhood development contributes to the progressive evolution of OSA because growth adapts to functional needs and that therapeutic intervention may counteract this evolution for normal growth to occur, ideally decreasing the symptoms of SDB. ${ }^{13}$ Moreover, there is evidence that maxillary expansion improves nasal breathing. ${ }^{14}$

\section{The objective of this retrospective study was}

i. To document if patients treated with maxillary expansion during childhood can benefit from this intervention concerning Sleep Disordered Breathing at adult age, especially focusing on cephalometric parameters.

ii. The secondary aim of our research is to try to find a screening tool for daily use in the orthodontic/dental office in children who are not yet diagnosed with OSA. Therefore we try to develop a tool that could help us in deciding which children should be referred for OSA screening, possibly including polysomnography, based on the cephalometric radiograph and on the symptoms they report.

\section{Methods}

\section{Ethical approval}

"All procedures performed in studies involving human participants were in accordance with the ethical standards of the institutional and/ or national research committee and with the 1964 Helsinki declaration and its later amendments or comparable ethical standards." This research was registered and approved by the Medical Ethics Committee of University Hospitals Leuven, with the registration number S56398.

\section{Informed consent}

Written, informed consent was received from all patients that took part in this study. An additional written informed consent was received from the parents or guardians if patients were less than 18 years of age. The Medical Ethics Committee of University Hospitals Leuven approved the study protocol and the consent procedure.

\section{Sample selection}

Within the period of September 2014-August 2015 we could include 27 consecutive subjects who attended a post-treatment checkup approximately ten to 25 years after they underwent orthodontic treatment during childhood. Inclusion criteria were:

\section{i. Orthodontic treatment including expansion}

ii. Good-quality lateral cephalometric head films available at the beginning of treatment (RCS group) and at the retention follow-up (RAS group) (Figure 1).

An untreated control group was used to compare cephalometric measurements both before treatment and at follow-up. The control group did not have a forced bite, cross bite or edge to edge occlusion, therefore maxillary expansion was not needed. To compare measurements before treatment, cephalometric radiographs of 50 children with similar age were used (RCCo group). To compare with the radiographs at follow-up, a control group of 50 adults with similar age as the RAS group was collected, they had never undergone maxillary expansion or any other orthodontic treatment in the past (RACo group) (Figure 1).

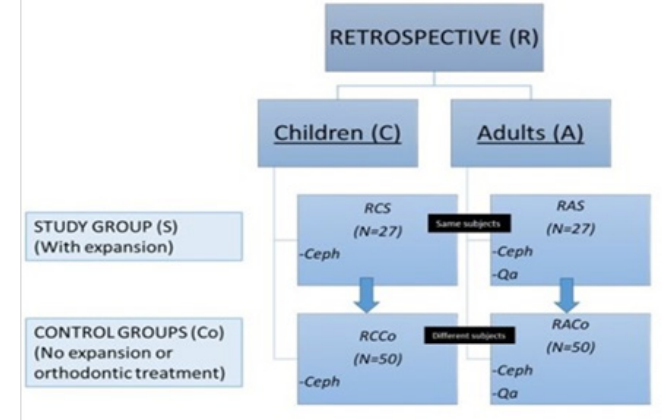

$R$, retrospective; $C$, children; $A$, adults; $S$, study group; $C O$, control group A cephalometric tracing was performed in all groups of the retrospective study (Ceph), in adults a questionnaire was also completed (Qa). Arrows indicate comparisons made between groups.

Figure I Overview of the retrospective study.

\section{Methodology}

Cephalometry: A conventional cephalometric radiograph was made at the beginning of orthodontic treatment with a Cranex Tome (Soredex, Tuusala, Finland) or a Siemens Orthophos C (Sirona Dental, Bensheim, Germany). For scanning the films an Epson Expression 1680 Pro flatbed scanner (Seiko Epson Corp., Nagano, Japan) was employed using Epson Twain scanning software approximately ten to 25 years later (Seiko Epson Corp.). At post-treatment follow-up a Veraviewepocs 2D (J. Morita Co., Kyoto, Japan) was used for a direct-digital cephalometric radiograph. Both lateral radiographs were traced and landmarks were placed employing Vistadent AT 3.1 software (GAC International, Bohemia, and New York, USA). Only head films adapted for magnification were used. Both angular and linear measurements were performed to observe posterior nasal airway space and factors associated with SDB. Craniofacial, pharyngeal and cranio-cervical measurements were performed. The measurements are described in Appendix 2 (Figure 2). ${ }^{15}$

Questionnaires: At follow-up, both the adult study (RAS group) and the control group (RACo group) were asked to complete a 
questionnaire. These questionnaires were based on the Dutch translation of the Spouse/Bed Partner Survey (SBPS), the Snore Outcomes Survey (SOS), the Epworth Sleepiness Scale (ESS) and supplementary questions of the Sleep Laboratory of the University Hospitals Leuven, Belgium. ${ }^{16-18}$ To detect abnormal daytime sleepiness a cut-off score of more than ten in the ESS is frequently used, though this should be confirmed by additional investigations. In both the RAS and RACo group, snorers were selected based on the answers on the SOS.

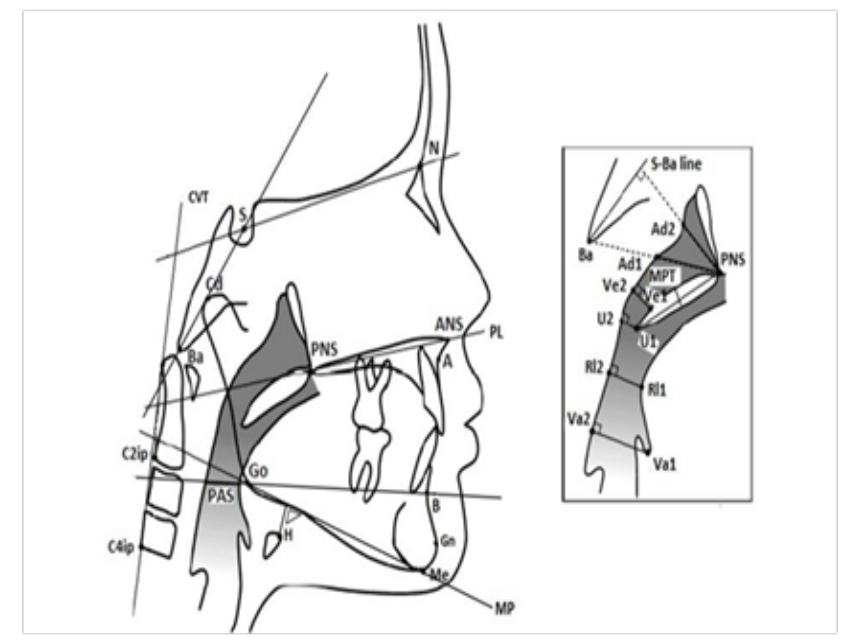

Figure 2 Cephalometric measurements, based on the article of PiriläParkkine. ${ }^{14}$

Table I Demographic information of the study and control group of the retrospective study before treatment and at follow-up

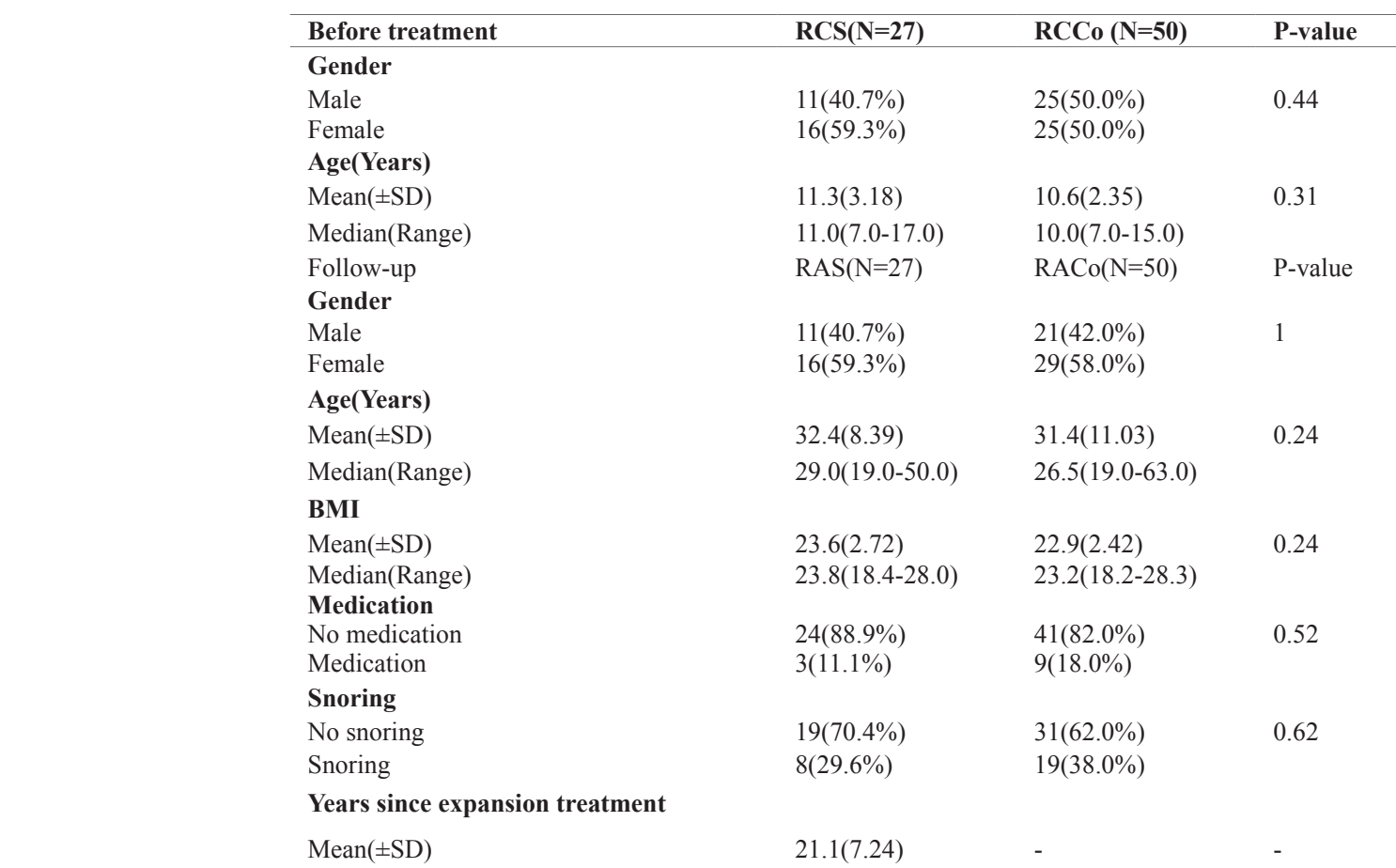

I. RCS, retrospective children study group; RCCo, retrospective children control group; RAS, retrospective adult study group; RACo, retrospective adult control group; SD, standard deviation; Range, minimum-maximum.

II. Variables presented with percentages are analyzed using a fishers exact test.Variables summarized by means, medians... are analyzed using a Mann-Whitney $\mathrm{U}$ test. All reported $\mathrm{P}$-values are two-sided.

\section{Statistics}

All analyses were accomplished working with SAS software, SAS system version 9.2 for Windows. For each cephalometric measurement individually, a linear model is used to compare the patients' mean values before and after treatment with the values of two control groups of comparable age. Variances are allowed to be specific in each of the four conditions. An extra covariance parameter is added to model the correlation of the values before treatment and at retention follow-up in the study groups.

The demographic variables and the results of the questionnaires are compared between patients and controls using non-parametric tests (Fishers exact and Mann-Whitney U tests). To compare the cephalometric assessments between patients and controls in the subset of snorers at follow-up Mann-Whitney $U$ tests have also been used. P-values lower than 0.05 are considered significant. Note that an individual significant P-value needs to be understood with attention because no correction for multiple testing is applied.

Assessment of method reliability: A random sample of 36 cephalometric tracings was completed twice on two independent moments, 2 weeks apart, by the same examiner. These tracings were also compared with those made by a second investigator. The intra- and inter-observer reliability was assessed using the intra-class correlation using an approach presented by Hayen, et al. ${ }^{19}$

\section{Results}

Demographic information was summarized in (Table 1). Because of the retrospective character of the study, no pre-treatment information about snoring, medication and BMI was known. 
General craniofacial and pharyngeal measurements are available in Tables $2 \& 3$. Before maxillary expansion, there were no differences between groups (RCS and RCCo) regarding cephalometric parameters related to OSA or nasal resistance, such as a longer soft palate (PNS-U1), a thicker soft palate (MPT), a smaller posterior airway space (PAS), a longer distance between the mandibular plane and the hyoid bone (H-MP) or a larger cranio-cervical angle (CVT-SN). ${ }^{20-24}$ At adult life, patients who underwent maxillary expansion (RAS) compared to control subjects with similar age (RACo) tended to have a significantly smaller CVT-SN $(\mathrm{P}=0.03)$ and a lower MPT $(\mathrm{P}=0.08)$. Children (RCS) undergoing maxillary expansion showed a significant decrease in PAS and an increase in H-MP when adult (RAS) and the same was observed concerning H-MP when comparing RCCo with RACo. Children (RCS) undergoing maxillary expansion did not show a significant change in MPT when adult (RAS); while, when comparing a control population of children (RCCo) with a control adult population $(\mathrm{RACo})$, MPT was significantly $(\mathrm{P}<0.01)$ larger in the adult population

When we compared questionnaires in adults between the RAS and RACo group no statistically significant differences in SDB symptoms, such as snoring and daytime sleepiness, were (Table 4).

A comparison was also made between snorers in the RAS and RACo groups to see if cephalometric measurements differed in snorers depending on treatment. Only the anterior facial height (N-ANS) was significantly larger in the snorers of the RAS group related to the RACo group $(\mathrm{P}=0.01)$.

\section{Reliability}

Good concordance was seen between the observers; for intraobserver reliability: the Intra-class Correlation Coefficient (ICC) ranged between 0.83 to 0.99 . The ICC varied in the range of 0.81 and 0.99 for inter-observer accuracy.

Table 2 Cephalometric measurements.

\begin{tabular}{|c|c|c|c|c|}
\hline & RCS group & RCCo group & RAS group & RACo group \\
\hline & Estimate (CI) & Estimate (CI) & Estimate (CI) & Estimate (CI) \\
\hline $\operatorname{SNA}\left({ }^{\circ}\right)$ & $81.0(79.3 ; 82.7)$ & $81.3(80.3 ; 82.3)$ & $79.0(77.7 ; 80.2)$ & $81.1(80.0 ; 82.2)$ \\
\hline $\operatorname{SNB}\left({ }^{\circ}\right)$ & $77.9(76.4 ; 79.5)$ & $75.8(74.9 ; 76.8)$ & $77.4(75.9 ; 78.9)$ & $77.8(76.7 ; 79.0)$ \\
\hline $\operatorname{ANB}\left({ }^{\circ}\right)$ & $3.1(1.8 ; 4.4)$ & $5.5(5.0 ; 6.1)$ & $1.6(0.3 ; 2.8)$ & $3.3(2.4 ; 4.1)$ \\
\hline $\mathrm{SN}-\mathrm{MP}\left({ }^{\circ}\right)$ & $35.2(32.8 ; 37.5)$ & $33.9(32.3 ; 35.5)$ & $35.1(32.5 ; 37.6)$ & $33.5(31.5 ; 35.5)$ \\
\hline PL-MP( $\left(^{\circ}\right)$ & $30.0(27.4 ; 32.7)$ & $27.1(25.5 ; 28.6)$ & $27.4(25.2 ; 29.7)$ & $26.6(24.8 ; 28.4)$ \\
\hline $\mathrm{N}-\mathrm{S}-\mathrm{Ba}\left({ }^{\circ}\right)$ & $128.2(126.0 ; 130.3)$ & $131.4(130.0 ; 132.8)$ & $129.2(127.0 ; 131.3)$ & $130.0(128.8 ; 131.3)$ \\
\hline ANS-PNS(mm) & $47.2(45.0 ; 49.3)$ & $47.2(46.4 ; 48.0)$ & $52.4(50.9 ; 53.8)$ & $51.2(50.1 ; 52.4)$ \\
\hline $\mathrm{Cd}-\mathrm{Gn}(\mathrm{mm})$ & $102.7(98.7 ; 106.7)$ & $98.5(96.9 ; 100.1)$ & $113.7(110.5 ; 117.0)$ & $111.2(108.7 ; 113.7)$ \\
\hline $\mathrm{N}-\mathrm{Me}(\mathrm{mm})$ & $105.0(100.8 ; 109.1)$ & $103.9(101.9 ; 105.9)$ & $117.5(114.6 ; 120.5)$ & $116.5(113.6 ; 119.3)$ \\
\hline N-ANS(mm) & $45.2(43.7 ; 46.8)$ & $46.4(45.3 ; 47.5)$ & $51.4(50.3 ; 52.6)$ & $50.5(49.4 ; 51.6)$ \\
\hline ANS-Me(mm) & $61.2(57.8 ; 64.5)$ & $59.3(57.8 ; 60.8)$ & $67.5(64.9 ; 70.0)$ & $67.5(65.3 ; 69.8)$ \\
\hline $\mathrm{S}-\mathrm{Go}(\mathrm{mm})$ & $66.8(63.8 ; 69.7)$ & $66.8(65.4 ; 68.2)$ & $76.2(73.7 ; 78.6)$ & $76.2(74.3 ; 78.2)$ \\
\hline $\mathrm{SN}(\mathrm{mm})$ & $64.1(62.0 ; 66.3)$ & $65.4(64.4 ; 66.4)$ & $68.5(66.8 ; 70.3)$ & $68.6(67.3 ; 69.9)$ \\
\hline PNS-Ad1(mm) & $20.9(19.1 ; 22.7)$ & $22.0(20.7 ; 23.3)$ & $21.8(20.3 ; 23.3)$ & $22.3(21.5 ; 23.0)$ \\
\hline PNS-Ad2(mm) & $15.4(13.9 ; 16.9)$ & $16.1(15.1 ; 17.0)$ & $17.2(15.6 ; 18.8)$ & $17.6(16.8 ; 18.4)$ \\
\hline Ve1-Ve2(mm) & $7.9(7.0 ; 8.8)$ & $7.9(7.2 ; 8.6)$ & $8.0(6.7 ; 9.2)$ & $8.5(7.7 ; 9.2)$ \\
\hline Va1-Va2(mm) & $13.8(12.7 ; 14.8)$ & $14.0(13.2 ; 14.7)$ & $14.4(13.6 ; 15.2)$ & $15.7(14.9 ; 16.4)$ \\
\hline R11-R12(mm) & $9.4(8.3-10.4)$ & $9.5(8.6 ; 10.4)$ & $7.4(6.5 ; 8.4)$ & $8.9(8.0 ; 9.9)$ \\
\hline U1-U2(mm) & $9.5(8.6 ; 10.4)$ & $9.1(8.4 ; 9.8)$ & $8.8(7.8 ; 9.8)$ & $9.3(8.6 ; 10.0)$ \\
\hline PNS-U1(mm) & $31.0(29.4 ; 32.5)$ & $31.7(30.7 ; 32.8)$ & $33.8(32.1 ; 35.6)$ & $34.4(33.4 ; 35.4)$ \\
\hline PAS(mm) & $11.7(10.6 ; 12.8)$ & $11.1(10.2 ; 12.0)$ & $10.0(9.0 ; 11.1)$ & $10.8(9.8 ; 11.7)$ \\
\hline $\mathrm{MPT}(\mathrm{mm})$ & 7.6(7.1;8.0) & $7.5(7.2 ; 7.8)$ & $7.7(7.0 ; 8.3)$ & $8.4(7.9 ; 8.8)$ \\
\hline $\mathrm{H}-\mathrm{MP}(\mathrm{mm})$ & $15.3(13.5 ; 17.0)$ & $13.1(11.9 ; 14.4)$ & $17.8(15.5 ; 20.2)$ & $16.4(15.0 ; 17.7)$ \\
\hline CVT-HOR $\left({ }^{\circ}\right)$ & $99.6(96.4 ; 102.7)$ & $98.0(95.6 ; 100.5)$ & $95.7(92.2 ; 99.1)$ & $100.7(97.6 ; 103.8)$ \\
\hline
\end{tabular}

I. RCS, retrospective children study group; RCCo, retrospective children control group; RAS, retrospective adult study group; RACo, retrospective adult control group.

II. Estimate $(\mathrm{Cl})$ : Mean from a multivariate regression model for longitudinal measures (with $95 \%$ Confidence Interval) 
Table 3 Overview of comparison of cephalometric measurements

\begin{tabular}{|c|c|c|c|c|c|}
\hline & \multicolumn{2}{|c|}{ In between groups $P$-value } & \multicolumn{2}{|c|}{ Within groups P-value } & \multirow{2}{*}{ Interaction P-value } \\
\hline & RCS vs RCCo & RAS vs RACo & RCS vs RAS & RCCo vs RACo & \\
\hline $\operatorname{SNA}\left({ }^{\circ}\right)$ & 0.73 & $0.01 *$ & $0.01 *$ & 0.79 & 0.09 \\
\hline $\mathrm{SNB}\left({ }^{\circ}\right)$ & $0.03 *$ & 0.65 & 0.44 & $0.01 *$ & $0.02 *$ \\
\hline $\mathrm{ANB}\left({ }^{\circ}\right)$ & $<0.01 *$ & $0.03^{*}$ & $0.01 *$ & $<0.01 *$ & 0.3 \\
\hline SN-MP( $\left(^{\circ}\right)$ & 0.36 & 0.33 & 0.93 & 0.76 & 0.84 \\
\hline $\operatorname{PL}-M P\left({ }^{\circ}\right)$ & 0.06 & 0.55 & $<0.01 *$ & 0.68 & 0.14 \\
\hline $\mathrm{N}-\mathrm{S}-\mathrm{Ba}\left({ }^{\circ}\right)$ & $0.02 *$ & 0.5 & 0.12 & 0.15 & $0.04 *$ \\
\hline ANS-PNS(mm) & 0.97 & 0.22 & $<0.01 *$ & $<0.01 *$ & 0.43 \\
\hline Cd-Gn(mm) & 0.06 & 0.2 & $<0.01 *$ & $<0.01 *$ & 0.46 \\
\hline $\mathrm{N}-\mathrm{Me}(\mathrm{mm})$ & 0.65 & 0.59 & $<0.01 *$ & $<0.01 *$ & 0.98 \\
\hline $\mathrm{N}-\mathrm{ANS}(\mathrm{mm})$ & 0.22 & 0.26 & $<0.01 *$ & $<0.01 *$ & 0.08 \\
\hline ANS-Me(mm) & 0.31 & 0.98 & $<0.01 *$ & $<0.01 *$ & 0.32 \\
\hline S-Go(mm) & I & 0.97 & $<0.01 *$ & $<0.01 *$ & 0.98 \\
\hline $\mathrm{SN}(\mathrm{mm})$ & 0.26 & 0.94 & $<0.01 *$ & $<0.01 *$ & 0.28 \\
\hline PNS-AdI (mm) & 0.32 & 0.54 & 0.28 & 0.7 & 0.6 \\
\hline PNS-Ad2(mm) & 0.47 & 0.65 & 0.1 & $0.02 *$ & 0.84 \\
\hline Vel-Ve2(mm) & I & 0.49 & 0.86 & 0.23 & 0.5 \\
\hline Val-Va2(mm) & 0.72 & $0.03 *$ & 0.25 & $<0.01 *$ & 0.18 \\
\hline RII-RI2(mm) & 0.84 & $0.03 *$ & $<0.01 *$ & 0.37 & 0.12 \\
\hline UI-U2(mm) & 0.45 & 0.4 & 0.23 & 0.63 & 0.22 \\
\hline PNS-UI (mm) & 0.42 & 0.58 & $<0.01 *$ & $<0.01 *$ & 0.84 \\
\hline $\mathrm{PAS}(\mathrm{mm})$ & 0.38 & 0.3 & $<0.01 *$ & 0.6 & 0.12 \\
\hline $\mathrm{MPT}(\mathrm{mm})$ & 0.74 & 0.08 & 0.74 & $<0.01 *$ & 0.08 \\
\hline $\mathrm{H}-\mathrm{MP}(\mathrm{mm})$ & 0.05 & 0.28 & $<0.01 *$ & $<0.01 *$ & 0.56 \\
\hline CVT-SN $\left({ }^{\circ}\right)$ & 0.44 & $0.03 *$ & 0.06 & 0.18 & $0.02 *$ \\
\hline
\end{tabular}

RCS, retrospective children study group; RCCo, retrospective children control group; RAS, retrospective adult study group; RACo, retrospective adult control group; Results from linear models.

Between-group, comparison of study and control group at each of the two time points.

Within-group, comparison of mean value before treatment and at retention follow-up in each of the two groups.

Interaction: test if the difference over time differs between groups.

P-value $\leq 0.05=*$ 
Table 4 Results of questionnaires of the retrospective part

Results: Likert-scale questions from sleep laboratory (Ranging 0-10)

\begin{tabular}{|c|c|c|c|c|c|}
\hline & \multicolumn{2}{|l|}{$\operatorname{RAS}(\mathbf{N}=27)$} & \multicolumn{2}{|l|}{$\operatorname{RACo}(\mathrm{N}=50)$} & \multirow{2}{*}{ P-Value } \\
\hline & $\operatorname{Mean}( \pm$ SD $)$ & Range & $\operatorname{Mean}( \pm$ SD $)$ & Range & \\
\hline Snoring & $2.3(2.43)$ & $0.0-10.0$ & $1.9(2.11)$ & $0.0-8.0$ & 0.46 \\
\hline Sleepiness during daytime & $2.4(1.98)$ & $0.0-6.0$ & $3.1(2.29)$ & $0.0-10.0$ & 0.31 \\
\hline Sleepiness during driving & $1.6(1.93)$ & $0.0-8.0$ & $1.6(1.61)$ & $0.0-5.0$ & 0.67 \\
\hline Tiredness in the morning & $2.8(2.11)$ & $0.0-8.0$ & $3.8(2.38)$ & $0.0-10.0$ & 0.12 \\
\hline Headache in the morning & $1.4(2.27)$ & $0.0-10.0$ & $1.4(1.94)$ & $0.0-7.0$ & 1 \\
\hline Sexual problems(disturbance libido) & $1.2(2.39)$ & $0.0-9.0$ & $0.3(0.71)$ & $0.0-3.0$ & 0.13 \\
\hline Sexual problems(erectile dysfunction) & $0.0(0.19)$ & $0.0-1.0$ & $0.1(0.36)$ & $0.0-2.0$ & 0.47 \\
\hline Nocturnal transpiration & $2.6(2.62)$ & $0.0-8.0$ & $1.8(1.78)$ & $0.0-6.0$ & 0.38 \\
\hline Nocturnal shortness of breath & $0.4(1.15)$ & $0.0-5.0$ & $0.6(1.51)$ & $0.0-7.0$ & 0.59 \\
\hline
\end{tabular}

Results: Yes/No questionnaires from sleep laboratory

\begin{tabular}{|c|c|c|c|c|c|}
\hline & Yes & No & Yes & No & P-Value \\
\hline $\begin{array}{l}\text { Were you ever involved in an accident } \\
\text { because of your tiredness? }\end{array}$ & $0.00 \%$ & $100.00 \%$ & $0.00 \%$ & $100.00 \%$ & / \\
\hline $\begin{array}{l}\text { Did your environment ever mention that you } \\
\text { stopped breathing? }\end{array}$ & $3.70 \%$ & $96.30 \%$ & $4.00 \%$ & $96.00 \%$ & 1 \\
\hline
\end{tabular}

Results: Epworth sleepiness scale and snore outcome survey

\begin{tabular}{|c|c|c|c|c|c|}
\hline & $\operatorname{Mean}( \pm$ SD $)$ & Range & $\operatorname{Mean}( \pm$ SD $)$ & Range & P-Value \\
\hline -ESS & $7.0(3.31)$ & $0.0-13.0$ & $6.7(3.88)$ & $0.0-18.0$ & 0.72 \\
\hline \multirow[t]{2}{*}{-SOS } & $0.8(0.16)$ & $0.2-0.9$ & $0.8(0.17)$ & $0.3-1.0$ & 0.53 \\
\hline & Yes & No & Yes & No & \\
\hline$-E S S \geq 11$ & $11.10 \%$ & $88.90 \%$ & $14.00 \%$ & $86.00 \%$ & 1 \\
\hline
\end{tabular}

RAS, retrospective adult study group; RACo, retrospective adult control group; Range, minimum-maximum; ESS, epworth sleepiness scale; SOS, snore outcome survey.

Results on questions used in the sleep laboratory: questions could be answered with a Likert-like scale ranging from 0 to I0(higher values mean increasing severity of the symptoms).

Variables presented with percentages are analyzed using a fishers exact test.Variables summarized by means, medians... are analyzed using a Mann-Whitney $U$ test. All reported $\mathrm{P}$-values are two-sided.

\section{Discussion}

The aim was to document whether patients treated with maxillary expansion during childhood can benefit from this intervention at adult age related to Sleep Disordered Breathing (SDB). According to our results, small cephalometric differences were seen in adult patients after maxillary expansion during childhood. Another aim was to examine whether SDB signs are frequent in participants who needed orthodontic maxillary expansion during childhood. In this way we try to find a screening aid for children that are not yet diagnosed with
OSA. This tool could help us in deciding which children should be referred for OSA screening.

\section{Cephalometric measurements}

Although in this study only small differences in airway width were reported, comparable studies did find differences. A study by Aloufi et al..$^{25}$ and Buccheri et al. ${ }^{26}$ demonstrated a significant raise in the upper pharyngeal airway space after RME. ${ }^{24-26}$ However, not all changes can be due to treatment. During growth and even throughout 
adult life, pharyngeal morphology changes. Johnston et al. ${ }^{20}$ reported a stable bony periphery but soft tissue alterations such as an increase of the sagittal depth of the nasopharynx decrease of the depth of the oropharyngeal airway and a thicker and also longer soft palate. ${ }^{20}$ This increase of soft tissue of the palate during adult life might be a contributing factor explaining why the occurrence of OSA rises with age. The lengthening of the soft palate during growth was confirmed in our analysis.

Concerning those parameters detectable in lateral radiographs, patients with OSA are often identified by a longer distance between the hyoid bone and the mandibular plane (H-MP), a smaller posterior airway space (PAS) and a longer soft palate (PNS-U1). ${ }^{21,22}$ Our measurements for PAS, soft palate length and MP-H (Figure 2) can be compared to the results of the control groups in other reported studies. ${ }^{21-23}$ Lyberg et al. ${ }^{27}$ found not only an increase in length of the soft palate but also in thickness in patients with OSA, which implies that the soft palate was larger. ${ }^{27}$ Although the MPT was smaller in the RAS related to the RACo group, this difference did not reach significance; nonetheless, the thickening over time was significantly higher $(\mathrm{P}<0.01)$ in the control group. This is in line with a possible positive effect of expansion of the maxilla on preventing thickening of the soft palate.

Breathing: A lower percentage of snorers were seen in the RAS group at follow-up when compared to the RACo group. No statistically significant differences were found. This difference in snoring might be correlated to the fact that maxillary expansion at childhood is beneficial to prevent SDB.

When a nasal obstruction is present, functional needs can cause the head to flex in order to breathe more easily through the mouth. With maxillary expansion, the nasal airway resistance can be improved and the cranio-cervical angle can decrease. ${ }^{24,28}$ In our retrospective longterm study, the cranio-cervical angle was similar between the RCS and RCCo group but was significantly more decreased at follow-up in the RAS group, which might support the fact that maxillary expansion had a positive effect.

Screening: A higher risk of SDB was seen in some subgroups of the population. Age, male sex, family history, smoking, obesity, alcohol use and craniofacial abnormalities can be considered as cofactors for increased risk of OSA. ${ }^{3}$ Since a favorable effect of maxillary expansion is seen on SDB signs in several studies, this might imply that a narrow upper jaw may be a cofactor of the disease, although further research is needed.

Battagel et al. ${ }^{29}$ concluded that lateral cephalograms can be useful for identifying OSA patients. ${ }^{29}$ Since a lateral cephalogram is routinely used in orthodontics, availability of these radiographs is higher than availability of an anterior-posterior radiograph or a threedimensional image. These additional records could also be helpful for evaluating maxillary expansion but are not made routinely. Therefore the validity of this study, even on a small sample, is to be able to recognize characteristics on a lateral cephalogram. Orthodontists using cephalography for orthodontic reasons can check and screen for OSA; by early referral and intervention or treatment, symptoms or complications can be limited. ${ }^{29}$

Limitations of the study: This study was marked by some limitations. Due to the limited number of adults, male and female results were pooled. A lateral cephalogram is a useful tool for evaluating skeletal and dental structures as well as soft tissues and airways. ${ }^{30}$ Nevertheless, it must be reminded that in these projections a three-dimensional structure is projected on a two-dimensional cephalogram. An anteriorposterior radiograph or dental casts for example could show more significant changes after maxillary expansion but because this study was retrospective, these records were not available. Furthermore, SDB such as OSA are multifactorial disorders with a complex etiology. It must be mentioned that some patients were treated orthodontically after expansion was completed, so differences can also be due to other treatment modalities. The control group before (RCCo group) and after treatment (RACo group) were not the same, which may imply differences. Although no expansion was needed in the control groups, it is possible that these subjects do have narrow maxillary arches which may also influence breathing.

The SOS and ESS are validated questionnaires. ${ }^{16,18,31}$ One of the multiple choice responses in the SOS was 'I don't know'. Therefore few questions were not scored and were considered as 'missing responses'. Because of lack or nonattendance at the consultation of a partner the SBPS was very often not filled in and hence excluded from the results. The Dutch version of the ESS is not validated so far. However, the ESS is a frequently used questionnaire to detect daytime tiredness.

\section{Conclusion}

Over a long-term of follow-up (from childhood to adulthood) changes in cephalometric measurements comparing patients with and without maxillary expansion were small but relevant related to SDB. Further research with long-term follow-up is required to see if maxillary expansion may have positive effects on SDB symptoms. Further research will also be necessary to see if the information from a questionnaire and/or cephalometric radiograph could help us in deciding which patients should be referred for further OSA screening.

\section{Acknowledgements}

There was no financial support.

\section{Conflicts of interest}

The authors declared that there are no conflicts of interest.

\section{References}

1. Sateia MJ. International classification of sleep disorders-third edition: highlights and modifications. Chest. 2014;146(5):1387-1394.

2. Punjabi NM. The epidemiology of adult obstructive sleep apnea. Proc Am Thorac Soc. 2008;5(2):136-143.

3. Peppard PE, Young T, Barnet JH, et al. Increased prevalence of sleepdisordered breathing in adults. Am J Epidemiol. 2013;177(9):1006-1014.

4. Young T, Skatrud J, Peppard PE. Risk factors for obstructive sleep Apnea in adults. JAMA. 2004;291(16):2013-2016.

5. Young T, Palta M, Dempsey J, et al. The occurrence of sleep-disordered breathing among middle-aged adults. N Engl J Med. 1993;328(17):1230 1235 .

6. Chan $\mathrm{CH}$, Wong B, Tang J, et al. Gender difference in snoring and how it changes with age: systematic review and meta-regression. Sleep Breath. 2012;16(4):977-986.

7. Pang KP, Terris DJ. Screening for obstructive sleep apnea: an evidencebased analysis. Am J Otolaryngol. 2006;27(2):112-118.

8. Ahrens A, McGrath C, Hagg U. A systematic review of the efficacy of oral appliance design in the management of obstructive sleep apnoea. Eur $J$ Orthod. 2011;33(3):318-324. 
9. Certal V, Nishino N, Camacho M, et al. Reviewing the systematic reviews in OSA surgery. Otolaryngol Head Neck Surg. 2013;149(6):817-829.

10. Kuhle S, Urschitz MS, Eitner S, et al. Interventions for obstructive sleep apnea in children: A systematic review. Sleep Med Rev. 2009;13(2):123131

11. Seto B, Gotsopoulos H, Sims MR, et al. Maxillary morphology in obstructive sleep apnoea syndrome. Eur J Orthod. 2001;23(6):703-714.

12. Katyal V, Pamula Y, Daynes CN, et al. Craniofacial and upper airway morphology in pediatric sleep-disordered breathing and changes in quality of life with rapid maxillary expansion. Am J Orthod Dentofacial Orthop. 2013;144(6):860-871.

13. Darendeliler A. Dentofacial Orthopedics. In: Lavigne G, et al. editors Sleep Medicine for Dentists: a practical overview. USA: Quintessence; 2009. p. 85-91.

14. Hershey H, Stewart BL, Warren DW. Changes in nasal airway resistance associated with rapid maxillary expansion. Am J Orthod.1976;69(3):274-284.

15. Pirila Parkkinen K, Lopponen H, Nieminen P, et al. Cephalometric evaluation of children with nocturnal sleep-disordered breathing. Eur $J$ Orthod. 2010;32(6):662-671.

16. Johns MW. Reliability and factor analysis of the epworth sleepiness Scale. Sleep. 1992;15(4):376-381.

17. Johns MW. A new method for measuring daytime sleepiness: the epworth sleepiness scale. Sleep. 1991;14(6):540-545.

18. Gliklich RE, Wang PC. Validation of the snore outcomes survey for patients with sleep-disordered breathing. Arch Otolaryngol Head Neck Surg. 2002;128(7):819-824.

19. Hayen A, Dennis RJ, Finch CF. Determining the intra-and inter-observer reliability of screening tools used in sports injury research. $J$ Sci and Med Sport. 2007;10(4):201-210.

20. Johnston CD, Richardson A. Cephalometric changes in adult pharyngeal morphology. Eur J Orthod. 1999;21(4):357-362.

21. Riley R, Guilleminault C, Herran J, et al. Cephalometric analyses and flowvolume loops in obstructive sleep Apnea patients. Sleep. 1983;6(4):303311.
22. Maltais F, Carrier G, Cormier Y, et al. Cephalometric measurements in snorers, non-snorers, and patients with sleep apnoea. Thorax. 1991;46(6):419-423.

23. Zucconi M, Ferini-Strambi L, Palazzi S, et al. Habitual snoring with and without obstructive sleep apnoea: the importance of cephalometric variables. Thorax. 1992;47(3):157-161.

24. Tecco S, Festa F, Tete S, et al. Changes in head posture after rapid maxillary expansion in mouth-breathing girls: a controlled study. Angle Orthod. 2005;75(2):171-176.

25. Aloufi F, Preston C, Zawawi K. Changes in the upper and lower pharyngeal airway spaces associated with rapid maxillary expansion. ISRN Dent. 2012;2012:290964.

26. Buccheri A, Dilella G, Stella R. Rapid palatal expansion and pharyngeal space. Cephalometric evaluation. Prog Orthod. 2004;5(2):160-171.

27. Lyberg T, Krogstad O, Djupesland G. Cephalometric analysis in patients with obstructive sleep apnoea syndrome: II. Soft tissue morphology. $J$ Laryngol Otol. 1989;103(3):293-297.

28. Solow B, Siersbæk-Nielsen S, Greve E. Airway adequacy, head posture, and craniofacial morphology. Am J Orthod. 1984;86(3):214-223.

29. Battagel JM, L'Estrange PR. The cephalometric morphology of patients with obstructive sleep apnoea (OSA). European J Orthod. 1996;18(6):557569 .

30. Pirilä-Parkkinen $\mathrm{K}$, Löppönen $\mathrm{H}$, Nieminen $\mathrm{P}$, et al. Validity of upper airway assessment in children: A clinical, cephalometric, and MRI study. Angle Orthod. 2011;81(3):433-439.

31. Chervin RD, Hedger K, Dillon JE, et al. Pediatric sleep questionnaire (PSQ): validity and reliability of scales for sleep-disordered breathing, snoring, sleepiness, and behavioral problems. Sleep Med. 2000;1(1):2132. 